\title{
Polymer matrices for carbon fiber-reinforced polymer composites
}

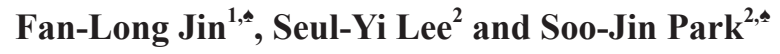 \\ ${ }^{1}$ School of Chemical and Materials Engineering, Jilin Institute of Chemical Technology, Jilin City 132022, People's Republic of \\ China \\ ${ }^{2}$ Department of Chemistry, Inha University, Incheon 402-751, Korea
}

\section{Article Info \\ Received 14 March 2013 \\ Accepted 5 April 2013 \\ *Corresponding Author \\ E-mail: jinfanlong@gmail.com sjpark@inha.ac.kr \\ Open Access \\ DOI: http://dx.doi.org/ \\ 10.5714/CL.2013.14.2.076 \\ This is an Open Access article distributed under the terms of the Creative Commons Attribution Non-Commercial License (http://creativecommons.org/licenses/ by-nc/3.0/) which permits unrestricted non-commercial use, distribution, and reproduction in any medium, provided the original work is properly cited.}

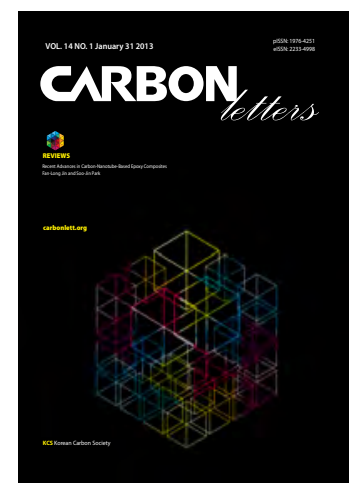

http://carbonlett.org

pISSN: $1976-4251$

elSSN: 2233-4998

Copyright $\odot$ Korean Carbon Society

\begin{abstract}
Carbon fibers (CFs) have high service temperature, strength, and stiffness, and low weight. They are widely used as reinforcing materials in advanced polymer composites. The role of the polymer matrix in the composites is to provide bulk to the composite laminate and transfer load between the fibers. The interface between the CF and the resin matrix plays a critical role in controlling the overall properties of the composites. This paper aims to review the synthesis, properties, and applications of polymer matrices, such as thermosetting and thermoplastic resins.
\end{abstract}

Key words: carbon fibers, polymer matrix, thermosetting resins, thermoplastic resins, composites

\section{Introduction}

Thermosetting resins are polymer materials that irreversibly cure and generally come in liquid form. Curing may be carried out by applying heat or through a chemical reaction or irradiation with infrared light, ultraviolet light, or an electron beam. Once they have been cured, the resins cannot be reheated and melted back to their liquid form. Thermosetting resins are easy to process and laminate, and pressure or heat is not necessarily needed for their formation. In addition, they are generally inexpensive, stronger than thermoplastics, and better suited than thermoplastics to higher temperatures. However, they are more brittle than thermoplastics [1-5].

Thermoplastic resins consist of long polymer molecules that are generally not crosslinked. The resin can be repeatedly melted and reused. Usually, no chemical change occurs when the thermoplastic is cured. Thermoplastic resins are often supplied as granules and heated to permit fabrication by conventional molding methods, such as injection molding, rotational molding, extrusion, vacuum forming, and compression molding. Thermoplastic resins have high impact strength, and they are recyclable. Further, they give off no emissions, and they can bond to other thermoplastics and be molded or shaped with reheating.

Carbon fibers (CF) have become an important reinforcing material in advanced composites because of their extremely high strength, stiffness, and heat-resistance, and low weight. Fiber-reinforced polymer composites are of great interest due to their very high strength-toweight and stiffness-to-weight ratios. These properties are sought after in materials used in aerospace, engineering, marine industries, and automobile industries [2].

In this paper, the synthesis and properties of polymer matrices, particularly thermosetting and thermoplastic resins, are reviewed in detail. In addition, the applications of polymer matrices for CF-reinforced polymer composites are discussed. 


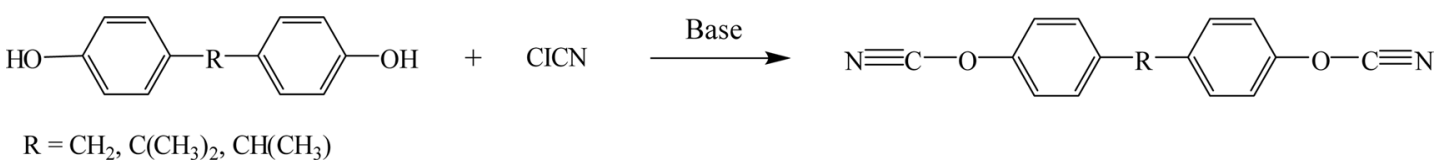

Fig. 1. Schematic outline for the synthesis of cyanate ester monomers.

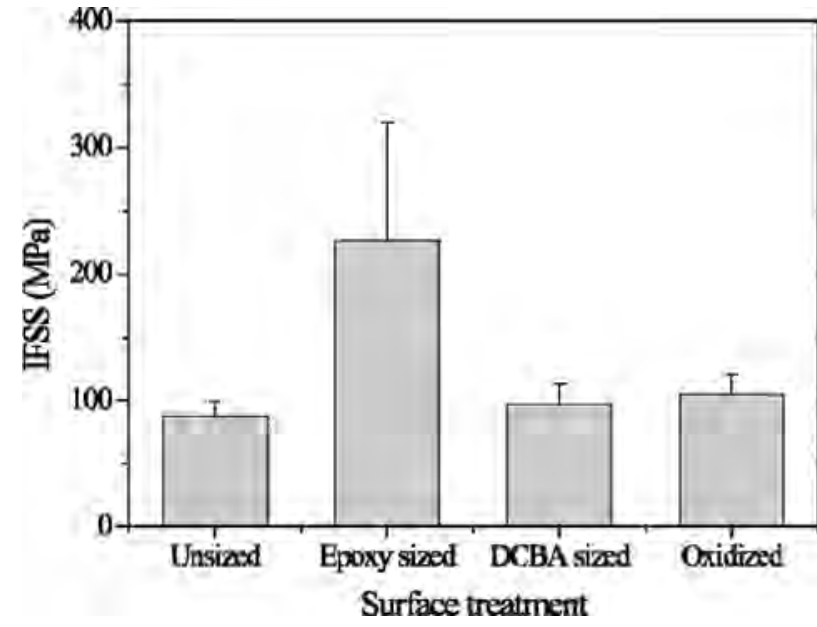

Fig. 2. Apparent IFSS data of DCBA/carbon fiber composites with different treatments by pull out measurements [2]. IFSS: interfacial shear strength, DCBA: bisphenol-A dicyanate.

\section{Thermosetting Resins}

\subsection{Cyanate ester resins}

Cyanate ester (CE) resins are a class of high-performance thermosetting resins consisting of esters that contain at least two cyanate functional groups $[1,2]$. Most commercial monomers can be represented by the structural model illustrated in Fig. 1.

CE resins can be cured by heating at elevated temperatures or they can be cured at lower temperatures in the presence of a suitable catalyst. The most common catalysts are transition metal complexes such as cobalt, copper, manganese, and zinc complexes. The chemistry of the curing reaction for $\mathrm{CE}$ resins is the trimerization of the three $\mathrm{CN}$ groups to form a triazine ring. The $\mathrm{CE}$ resins have two cyanate groups that facilitate the formation of a three-dimensional polymer network structure [3].

$\mathrm{CE}$ resins homopolymerize into a thermosetting material suitable for use in higher-performance composites such as structural composites and those for printed circuit boards and radomes. These resins have good processability, shelf life, and compatibility with a variety of reinforcements. Fully cured bisphenol-E CE has a glass transition temperature $\left(\mathrm{T}_{\mathrm{g}}\right)$ and a decomposition temperature $\left(\mathrm{T}_{\mathrm{d}}\right)$ at $5 \mathrm{wt} \%$ loss of $274^{\circ} \mathrm{C}$ and $438^{\circ} \mathrm{C}$, respectively $[4,5]$.

Marieta et al. [2] studied the effect of surface treatment on the interfacial shear strength (IFSS) of bisphenol-A dicyanate (DCBA)/PAN-based CF composites. Fig. 2 shows the apparent IFSS values of the composites with different treatments. The results indicated that the commercial sizing of epoxy was effective in promoting adhesion because of the chemical reactions taking place between the epoxy sizing and DCBA during the curing process.

\subsection{Epoxy resins}

Epoxy resins are low-molecular-weight pre-polymers containing more than one epoxide group:<smiles>[R]C1CO1</smiles>

Thermosetting epoxy resins are cured using a wide variety of curing agents via curing reactions. Epoxy resins have a wide range of applications including their use in fiber-reinforced materials, general-purpose adhesives, high-performance coatings, and encapsulating materials.

\subsubsection{Bisphenol-A epoxy resins}

Diglycidyl ether of bisphenol-A (DGEBA) is produced by reacting epichlorohydrin with bisphenol-A in the presence of a basic catalyst. Fig. 3 shows the chemical structure of DGEBA.

The properties of the DGEBA resins depend on the value of $\mathrm{n}$, which is the number of repeating units and is commonly known as the degree of polymerization. Low-molecularweight molecules tend to be liquids and higher-molecularweight molecules tend to be more viscous liquids or solids. DGEBA has been used commercially as a raw material and is the primary chemical building block for a broad spectrum of materials $[6,7]$.

Park et al. [8] demonstrated the effect of fiber-polymer interactions on the fracture toughness behavior of CF-reinforced DGEBA epoxy matrix composites. Fig. 4 shows the evolution of the critical stress intensity factor $\left(\mathrm{K}_{\mathrm{IC}}\right)$ of DGEBA/CF composites as a function of electric current density. The $\mathrm{K}_{\mathrm{IC}}$ of the composites continually increases with increased current densities of the treatments up to $0.4 \mathrm{~A} / \mathrm{m}^{2}$. This is due to the increased interfacial adhesion between the fibers and matrix.

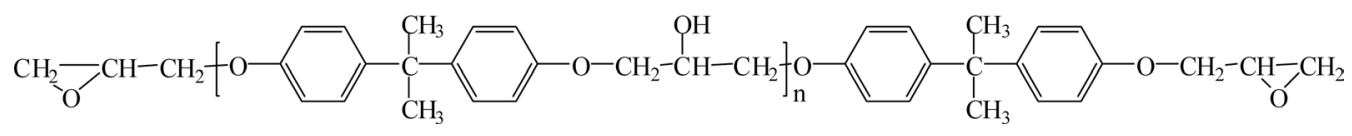

Fig. 3. Chemical structure of diglycidyl ether of bisphenol-A. 


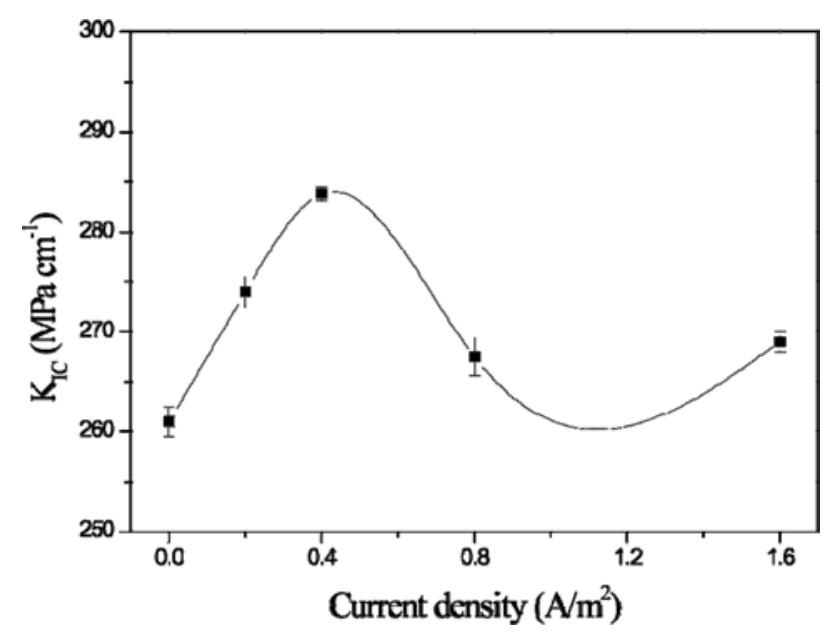

Fig. 4. Effect of current density on $\mathrm{K}_{\mathrm{I}}$ of diglycidyl ether of bisphenolA/carbon fiber composites [8].

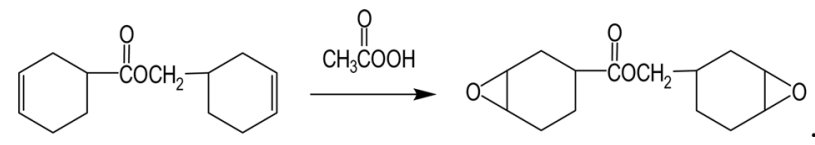

Fig. 5. Schematic outline for the synthesis of $3^{\prime}, 4^{\prime}-$ epoxycyclohexylmethyl 3,4-epoxycyclohexanecarboxylate.

\subsubsection{Cycloaliphatic epoxy resins}

The cycloaliphatic epoxy resin, 3',4'-epoxycyclohexylmethyl 3,4-epoxycyclohexanecarboxylate is synthesized by reacting 3'-cyclohexenylmethyl 3-cyclohexenecarboxylate with peracetic acid, as shown in Fig. 5.

The cycloaliphatic epoxy resin has an aliphatic backbone and a fully saturated molecular structure, which are contributing factors relating to its excellent UV stability, good weatherability, and excellent electrical properties. This epoxy resin, which has a high epoxide content, also exhibits a high crosslink density, $\mathrm{T}_{g}$, and heat distortion temperature. These properties are crucial for resins used to fabricate structural components requiring high-temperature service. Since this is a short chain epoxy resin, it has a low viscosity, which allows for rapid fiber wet-out in commonly used processes

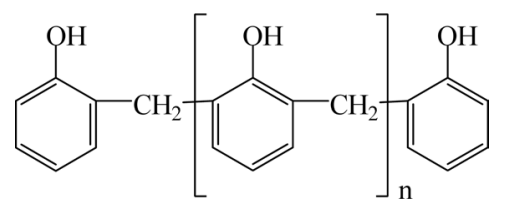

Fig. 8. Chemical structure of novolac resins.

that include filament winding, pultrusion, and resin transfer molding [9].

\subsubsection{Trifunctional epoxy resins}

A trifunctional epoxy resin, trimethylol propane-N-triglycid$\mathrm{yl}$ ether, is prepared by the reaction of trimethylol propane and epichlorohydrin, as shown in Fig. 6.

The epoxy resin is a low-viscosity, non-crystalline, plastic material, and it can be cured at low temperatures $[10,11]$.

\subsubsection{Tetrafunctional epoxy resins}

Tetrafunctional epoxy resins are synthesized by reacting 1,3-diaminobenzene or 4,4'-aminodiphenyl methane with epichlorohydrin, as shown in Fig. 7.

Tetrafunctional epoxy resins with high epoxy functionality have high cross-linking densities, and they are used in applications where high-temperature resistance is required. The cured epoxy resins show excellent chemical resistance, high modulus, good UV-blocking effect, and good thermal stability $[12,13]$.

Chen et al. [14] studied the DGEBA/CF and 4,4'-tetradiglycidy diaminodiphenol methane (TGDDM)/CF filament wound composites. The results indicated that the two kinds of resins (DGEBA and TGDDM) with the hardener 4,4'-diaminodiphenyl methane (DDM) or DDM/diethyltoluene diamine (DETDA) had higher tensile properties than the resins cured with the methyltetrahydrophthalic anhydride (MeTHPA) hardener. The TGDDM resin casts showed tensile strengths close to those of the DGEBA resin casts, but the former had longer elongations.

\subsubsection{Novolac resins}

Novolac resins are synthesized by the reaction of a molar excess of phenol with formaldehyde under an acidic catalyst such as oxalic acid, hydrochloric acid, or sulfonic acid. Fig. 8 shows the chemical structure of novolac resins.

$$
\mathrm{CH}_{3} \mathrm{CH}_{2}-\underset{\mathrm{CH}_{2} \mathrm{OH}}{\stackrel{\mathrm{C}}{\mathrm{C}}-\mathrm{CH}_{2} \mathrm{OH}}+\mathrm{CH}_{2} \stackrel{\mathrm{OH}}{-}=\mathrm{CH}_{\mathrm{CH}} \mathrm{Cl}
$$

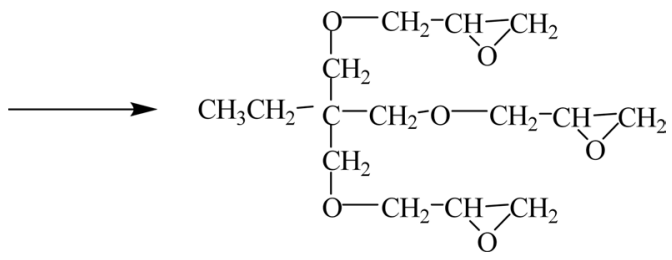

Fig. 6. Schematic outline for the synthesis of trimethylol propane- $N$-triglycidyl ether.
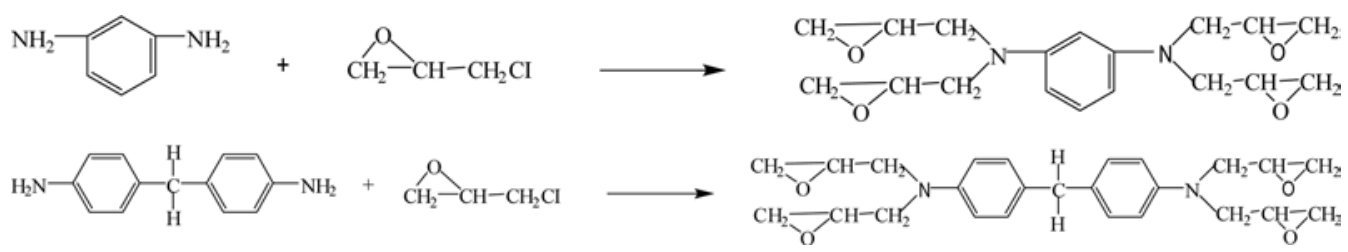

Fig. 7. Schematic outline for the synthesis of tetrafunctional epoxy resins. 


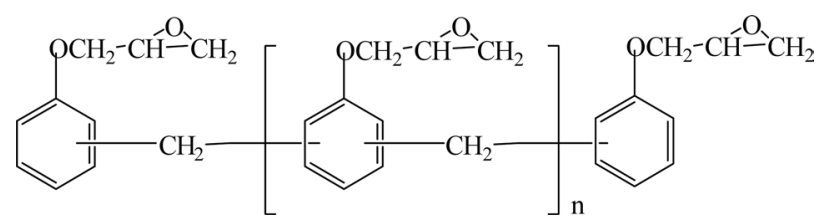

Fig. 9. Chemical structure of novolac epoxy resins.

Novolac resins are solid at room temperature and will soften and flow between $65^{\circ} \mathrm{C}$ and $105^{\circ} \mathrm{C}$. The number average molecular weight (Mn) of a standard phenol novolac resin is between 250 and 900 . Novolac resins are soluble in many polar organic solvents such as alcohols and acetone, but they are insoluble in water [15].

\subsubsection{Novolac epoxy resins}

Novolac epoxy resins are glycidyl ethers of phenolic novolac resins that have been synthesized by reacting phenolic novolac resin with epichlorohydrin. Fig. 9 shows the chemical structure of novolac epoxy resins. Because an additional curing agent is required to complete the curing of the resin, the industry commonly refers to novolac resins as "two-step" products.

The multiple epoxide groups in novolac epoxy resins contribute to their high cross-linking densities, which results in their excellent thermal, chemical, and solvent-resistance properties. Novolac epoxy resins are widely used to formulate the molding compounds for microelectronics packaging because of their superior performance at elevated temperature, excellent moldability characteristics and mechanical properties, superior electrical properties, and heat and humidity resistance $[16,17]$.

\subsubsection{Epoxy curing agents}

A wide variety of curing agents are used for curing epoxy resins. The cure kinetics and $\mathrm{T}_{\mathrm{g}}$ of cured epoxy resins are dependent on the molecular structure of the curing agents. The stoichiometry of the epoxy/curing agent system will be reflected in the properties of the cured epoxy resins. An agent that is not consumed in the reaction is known as a catalytic curing agent. A reactive curing agent is consumed in the reaction and is generally used in much greater amounts than catalytic curing agents. In this case, the curing agents react with the resin molecules, and they are coupled directly into the cured system as structural members of the polymer.

Epoxy curing agents can be divided into amine-type curing agents (such as triethylenetetramine and DDM), alkali curing agents (such as imidazole type and tertiary amines), anhydrides (such as phthalic anhydride [PA] and nadic methyl anhydride), and catalytic curing agents (such as $N$-benzylpyrazinium hexafluoroantimonate $[\mathrm{BPH}]$ and $N$-benzylquinoxalinium hexafluoroantimonate $[\mathrm{BQH}])[18-21]$. The chemical structures of DDM, $\mathrm{PA}, \mathrm{BPH}$, and $\mathrm{BQH}$ are shown in Fig. 10.

\subsubsection{Curing process}

The epoxy curing process is a chemical reaction in which the epoxide groups in the epoxy resins react with a curing agent to form a highly cross-linked, three-dimensional network [22-24].

1) Room-temperature curing

Epoxy resin curing that takes place at room temperature uses curing agents (such as aliphatic polyamine). Room-temperature curing provides a lower $T_{g}$, higher flexibility, greater impact resistance, and greater electrical and thermal shock resistance.

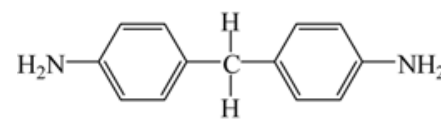

(a) DDM

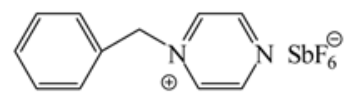

(c) $\mathrm{BPH}$<smiles>O=C1OC(=O)c2ccccc21</smiles>

(b) PA

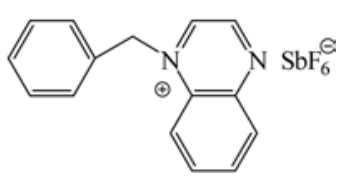

(d) $\mathrm{BQH}$
Fig. 10. Chemical structures of DDM, PA, BPH, and BQH. DDM: 4,4'-diaminodiphenyl methane, PA: phthalic anhydride, $\mathrm{BPH}, \mathrm{N}$-benzylpyrazinium hexafluoroantimonate, $\mathrm{BQH}$ : $\mathrm{N}$-benzylquinoxalinium hexafluoroantimonate.

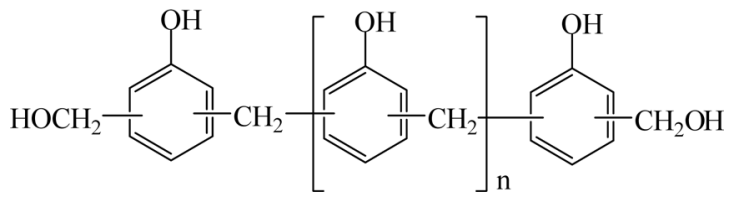

Fig. 11. Chemical structure of resol resins.

\section{2) Heat curing}

Generally, epoxy resins are cured with curing agents that react at elevated temperatures. These cured epoxy resins have a higher $\mathrm{T}_{\mathrm{g}}$, greater tensile strength, higher heat resistance, and greater chemical resistance.

3) Photocuring

Epoxy resins can be cured using a photoinitiator. The curing reaction takes place in the presence of infrared or ultraviolet light, or by placing the reactants in the path of an electron beam.

\subsection{Phenolic resins}

Phenolic resins are normally prepared from phenol and formaldehyde. Phenolic resins can be divided into either resol or novolak resins according to the preparation methods used [25-28].

\subsubsection{Resol resins}

Resol resins were synthesized by reacting a molar excess of formaldehyde with phenol in the presence of a catalytic base. Fig. 11 shows the chemical structure of resol resins.

When an excess of formaldehyde is used in the synthesis of resol resins, a sufficient number of methylol and dibenzyl ether groups remain reactive, i.e., available for completing the polymerization and curing the resin without the need for incorporating an additional cure agent such as hexamethylenetetramine. For this reason, the industry commonly refers to resol resins as "single-stage" products. The typical $\mathrm{M}_{\mathrm{n}}$ of a straight phenol resol resin is between 200 and 450 .

\subsubsection{Novolak resins}

Novolak resins were synthesized by reacting a molar excess of phenol with formaldehyde in the presence of a catalytic acid Fig. 12 shows the chemical structure of novolak resins. 


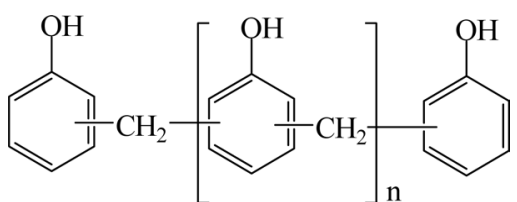

Fig. 12. Chemical structure of novolak resins.

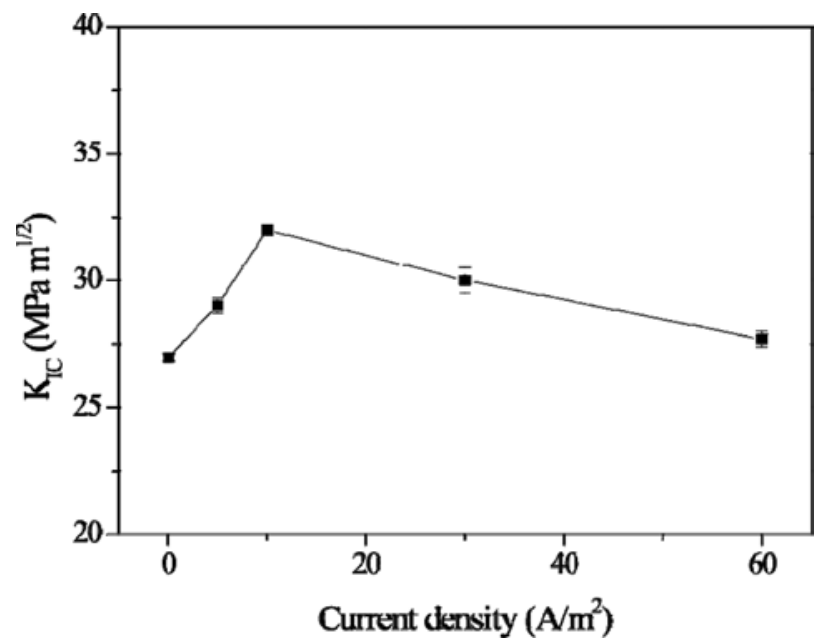

Fig. 13. Evolution of $K_{1 c}$ of phenolic resin/carbon fiber composites with current density [25].

The reaction creates a methylene bridge at either the ortho position or the para position of the phenolic aromatic rings. These phenolic resins are unable to react further without the addition of a curing agent. Because an additional agent is required to complete the curing of the resin, the industry commonly refers to novolac resins as "two-stage" products. The most common curing agent for novolak resins is hexamethylenetetramine.

Park and Jang [26] demonstrated the interfacial characteristics and fracture toughness of electrolytically Ni-plated CFreinforced phenolic resin composites. Fig. 13 shows the results of the $\mathrm{K}_{\mathrm{IC}}$ tests of the composites as a function of current density. The $\mathrm{K}_{\mathrm{IC}}$ increased with an increasing current density up to $10 \mathrm{~A} /$ $\mathrm{m}^{2}$. This high fracture toughness can be attributed to the presence of nickel functional groups and a higher number of oxide functional groups present on the $\mathrm{CF}$.

\subsection{Polyester resins}

Polyester resins are unsaturated resins formed from the reaction of dibasic organic acids with polyhydric alcohols, as shown in Fig. 14.

Polyester resins have relatively good resistance to UV radiation. They are long lasting and highly water resistant. These resins comprise the most commonly used polymer matrix in the marine and composite industries. The resins are used in sheet molding compounds, bulk molding compounds, and in the toner<smiles>[R]C(=O)N([R2])C([R])=O</smiles>

Fig. 15. Chemical structure of polyimide.<smiles>Cc1ccc2c(c1)C(=O)N(C(C)(C)C)C2=O</smiles>

(a) Aromatic PIs<smiles>[R]C(=O)N([R])C(=O)C(C)(C)C</smiles>

(b) Linear PIs
Fig. 16. Chemical structures of aromatic and linear polyimides (PIs).

used in laser printers. They are commonly used in auto repair, casting, adhesives, and wood filling. These resins can be used with any type of fiberglass CF or Kevlar [27-29].

Polyester resins are classified as thermosetting resins, and they can be cured exothermically to a solid with the addition of the curing agent. Generally, organic peroxides such as benzoyl peroxide and methyl ethyl ketone peroxide (MEKP) are used as the curing agents.

Some commercially important linear polyesters include polyglycolic acid, polylactic acid, polycaprolactone, polyethylene terephthalate, and polybutylene terephthalate.

Vilcakova et al. [32] demonstrated the electrical conductivity of polyester resin/CF composites in the percolation threshold region. A steep conductivity increase at a relatively low CF content $(0.7 \mathrm{vol} \%)$ was observed, which was thought to be caused by a special mechanism involved in the formation of the intrinsic fibrous structure of the composites.

\subsection{Polyimide resins}

Polyimide (PI) is a polymer constructed from imide monomers. Fig. 15 shows the structure of PI [33-35].

PIs can be divided to aliphatic PIs where the atoms of the imide group are part of a linear chain and aromatic PIs where the imide group is part of a cyclic unit in the polymer chain, as shown in Fig. 16.

PIs possess a greater resistance to heat than any other unfilled organic material. Unlike most plastics, PIs are available in laminates and shapes, molded parts, and stock shapes. PI parts are fabricated by techniques ranging from powder-metallurgy methods to conventional injection, transfer, compression molding, and extrusion.

PIs have low dielectric constants, and they can be polishable to an angstrom-level surface finish. In addition, they have excellent dimensional stability and flexibility, and they exhibit low water absorption. They have high temperature

$$
\mathrm{HO}-\mathrm{R}-\mathrm{OH}+\mathrm{HOOC}-\mathrm{R}^{\prime}-\mathrm{COOH}
$$

Fig. 14. Schematic outline for the synthesis of polyester resins.
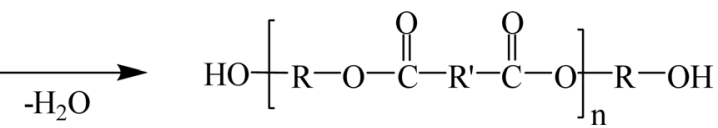


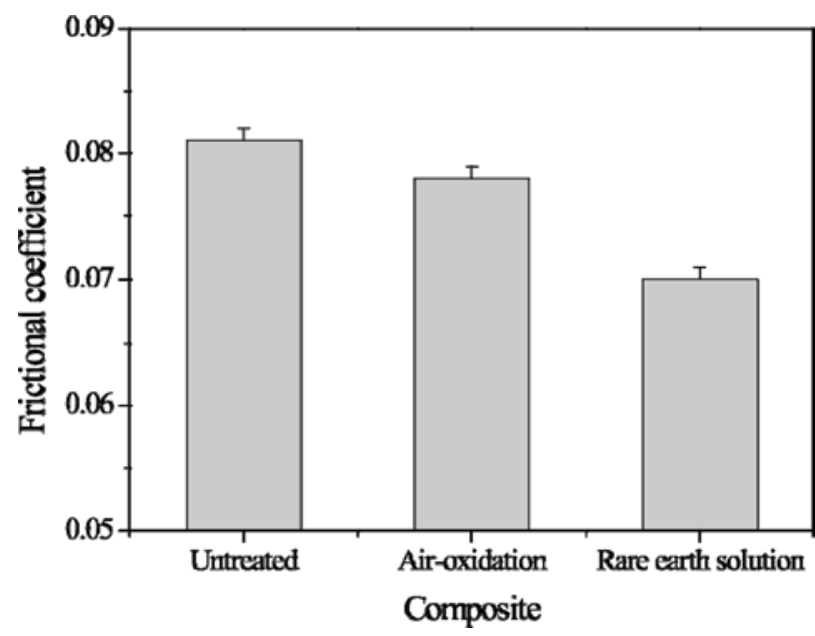

Fig. 17. Effect of surface treatment on friction of polyimide/carbon fiber composites [36].

stability, excellent machinability, exceptional mechanical strength, and low coefficient of thermal expansion, and they exhibit low outgassing. In addition, they are non-contaminating. They are used in place of metals and glass in many highperformance applications in electronics, automotive design, and the aerospace industry.

PIs are solid, heat-resistant, incombustible substances of predominantly amorphous structure, with Mn of 50 000-150 000 and a density of $1.35-1.48 \mathrm{~g} / \mathrm{cm}^{3}$ at $20^{\circ} \mathrm{C}$. Most PIs do not dissolve in organic solvents and are inert to the action of oils. Further, most remain virtually unchanged under the action of dilute acids. They are hydrolyzed by alkaline substances and superheated steam. PIs are resistant to ozone, $\gamma$-rays, fast electrons and neutrons, and are highly resistant to heat.

$\mathrm{Li}$ and Cheng [36] studied the friction and wear properties of surface-treated CF-reinforced PI composites under oil-lubricated conditions. As shown in Fig. 17, the friction coefficients of air-oxidized and rare earth solution treated CF-reinforced PI composites are lower than those of untreated CF-reinforced PI composites. This would indicate that surface modification can improve the interfacial adhesion and compatibility between the $\mathrm{CF}$ and the PI matrix.

\subsection{Vinyl ester resins}

Vinyl ester (VE) is a resin produced by the esterification of an epoxy resin with an unsaturated monocarboxylic acid. These resins combine the advantages of both epoxy and polyester resins. The resins possess the higher flexibility that is observed in epoxy resins with an ease of processing that is like that involved in the synthesis of polyesters [37].

VE resins are stronger than polyester resins and cheaper to make than epoxy resins. VE resins have lower viscosities than

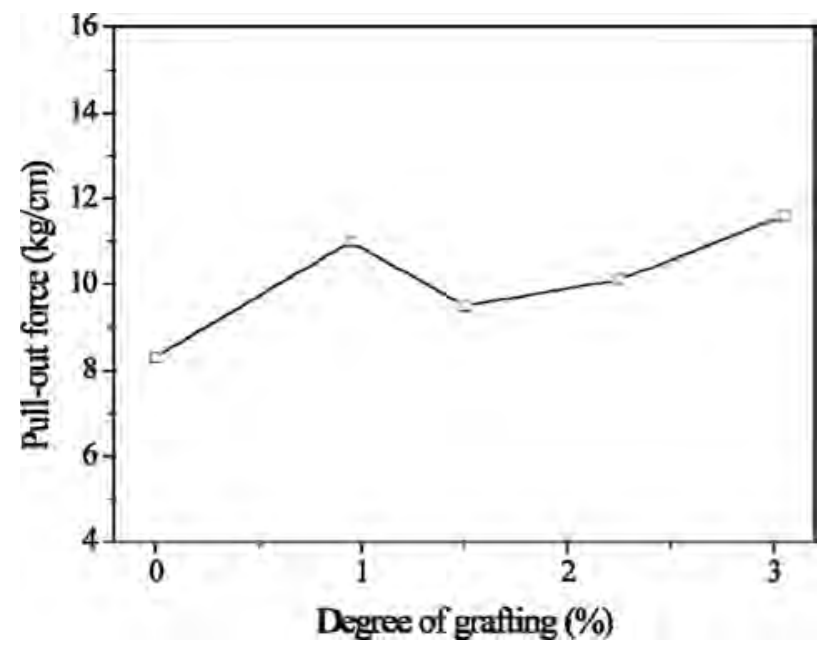

Fig. 19. Pull-out force of the grafted carbon yarn as a function of the degree of grafting in adipic acid divinyl ester [40].

polyester and epoxy resins. VE resins offer better resistance to moisture absorption than polyester resins. It is also known that VE resins bond extremely well to fiberglass but bond poorly to Kevlar and $\mathrm{CF}$ due to the nature of those two more exotic fibers [38].

Bisphenol-A epoxy VE resin, as shown in Fig. 18, is resistant to a wide range of acids, alkalis, bleaches, and organic compounds that are commonly used in many industrial chemical processing applications.

VE resins are exceptionally reactive and cure rapidly. Peroxides, such as MEKP, dicumyl peroxide, di(t-butylperoxy) cyclohexane, and tertiary-butyl peroxybenzoate, were used as initiators for curing VE systems [39]. Cured VE is more flexible and has greater fracture toughness than polyester. VE can also withstand temperatures of up to $<200^{\circ} \mathrm{C}$ without distorting.

Yamada et al. [40] demonstrated the plasma-graft polymerization of a monomer with double bonds onto the surface of CF and evaluated its adhesion to a VE resin. Fig. 19 shows the pullout force of the yarns, which were grafted by poly(adipic acid divinyl ester) chains and were then embedded in the cured VE resin/benzoyl peroxide/ $N, N$-dimethylaniline mixture, as a function of the degree of grafting. The pull-out force increased with the increasing degree of grafting.

\section{Thermoplastic Resins}

\subsection{Acrylonitrile butadiene styrene resins}

Acrylonitrile butadiene styrene (ABS) is a terpolymer of acrylonitrile, butadiene, and styrene. Fig. 20 shows the chemical structure of ABS. Many industrial methods such as bulk, bulk-

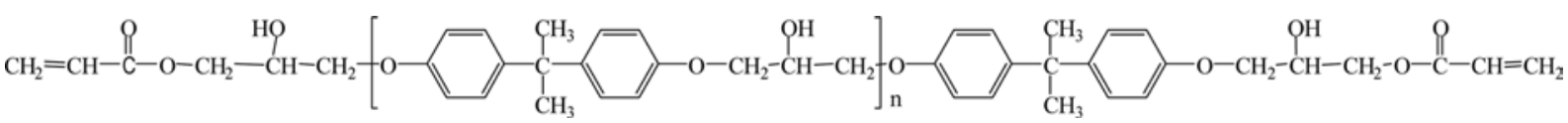

Fig. 18. Chemical structure of bisphenol-A epoxy vinyl ester. 


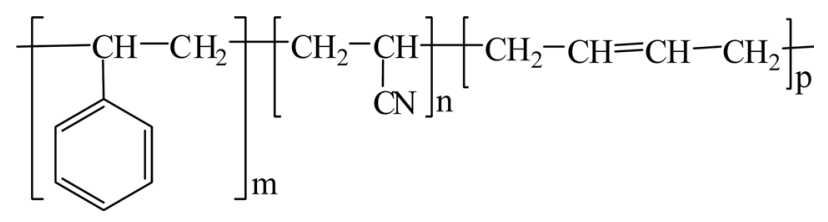

Fig. 20. Chemical structure of acrylonitrile butadiene styrene.

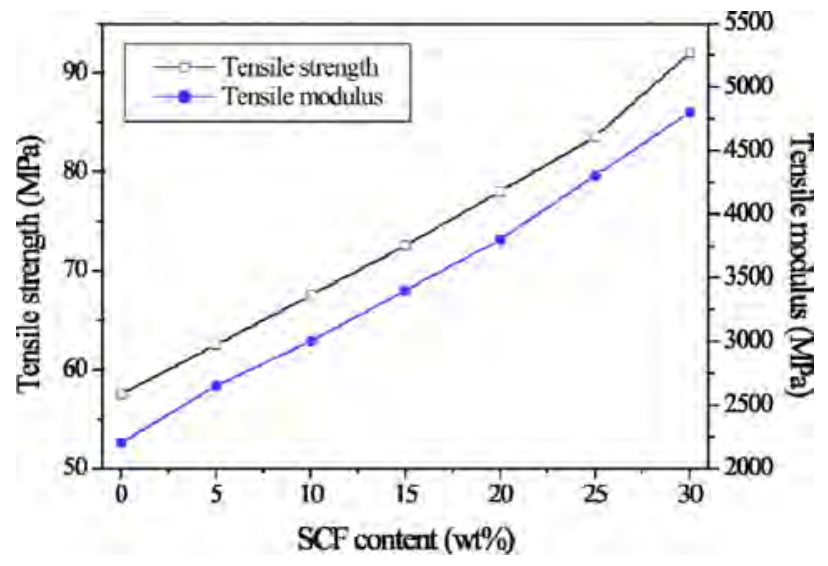

Fig. 21. Tensile properties of acrylonitrile butadiene styrene/short carbon fiber (SCF) composites [42].

suspension, emulsion, and emulsion graft-doped legitimate are used to prepare ABS resins.

Common ABS resin compositions are about half styrene with the balance divided between butadiene and acrylonitrile. The higher the percentage of acrylonitrile in the ABS resin, the better the heat-resistance, rigidity and solvent-resistance will be. However, the opposite is true for the flow character. The heat-resistance and solvent-resistance for these resins are better than they are for high impact polystyrene (HIPS). The impact strength and the tensile strength as well as the surface hardness of ABS are better than those observed in HIPS. ABS resin is a tough, light, economical, heat- and stain-resistant, excellent engineering plastic $[41,42]$.

$\mathrm{Li}$ and Cai [42] studied the CF surface treatment and the addition of PA6 on the tensile properties of ABS composites. Fig. 21 shows the effects of the short $\mathrm{CF}$ (SCF) content on the tensile properties of ABS/SCF composites. Increasing the SCF content increases the tensile strength and modulus of the composites, which is in agreement with the well-known equation of Kelly and Tyson for mixing short fiber-reinforced composite materials.

\subsection{Polyamide resins}

Polyamide (PA) is a polymer containing monomers of amides joined by peptide bonds. PAs are resins that include a $\mathrm{CO}-\mathrm{NH}$ functional group in their polymer backbone. They may be pro-

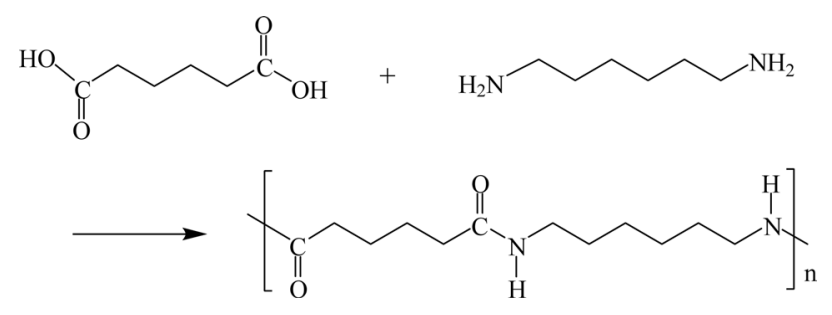

Fig. 22. Schematic outline for the synthesis of nylon 66 .

duced by the interaction of an amine $\left(\mathrm{NH}_{2}\right)$ group and a carboxyl $(\mathrm{COOH})$ group, or they may be formed by the polymerization of amino acids or amino-acid derivatives. They can occur both naturally and artificially. PAs are commonly used in textiles, automotive, carpet, and sportswear because of their extreme durability and strength $[43,44]$.

Poly(hexamethylenediamine adipamide) (Nylon 66, PA66) is one of the most widely used semi-crystalline engineering thermoplastic resins. Nylon 66 is synthesized by reacting adipic acid with hexamethylene diamine, as shown in Fig. 22.

Nylon-66 is a semicrystalline polyamide commonly used in fiber applications such as carpeting, clothing, and tire cord. It is also used as an engineering material in bearings and gears due to its good abrasion resistance and self-lubricating properties [45]. Nylon 66 has good sliding properties, is abrasion resistant, has high tensile strength, a higher melting point, and is electrically insulating. Because of these properties it is widely used in gear wheels, friction strips, piston guides, impact plates, cam discs, and much more [46].

Botelho et al. [44] studied the mechanical behavior of CFreinforced PA composites. Their results indicate that an increase in the fiber volume fraction improved the mechanical properties of the composites.

\subsection{Polycarbonates resins}

Polycarbonate $(\mathrm{PC})$ is produced by the reaction of bisphenol A and phosgene $\mathrm{COCl}_{2}$. The overall reaction is shown in Fig. 23.

PC has the advantage of having a uniquely high impact strength and exceptional clarity, which makes it a valuable material for use in bulletproof windows, break resistant lenses, compact discs, etc. $[47,48]$. PCs are used mainly as molding compounds. The commercially important PCs in use include bisphenol A and diphenyl carbonate. These polymers are clear plastics with a slight yellow discoloration. They have excellent electrical properties and high impact strength [49].

Choi et al. [50] demonstrated the production and characterization of $\mathrm{PC}$ composite sheets reinforced with vapor grown CF (VGCF). Fig. 24 shows the Young's modulus of PC/VGCF cast and rolling composites reinforced with various amounts of VGCF. The Young's modulus of both the composites increased with an increase in the VGCF content.<smiles>CC(C)(c1ccc(O)cc1)c1ccc(O)cc1</smiles><smiles>O=C(Cl)Cl</smiles><smiles>CC(C)(C)Oc1ccc(C(C)(C)c2ccc(OC(=O)C3(C)CC3)cc2)cc1</smiles>

Fig. 23. Schematic outline for the synthesis of polycarbonate. 


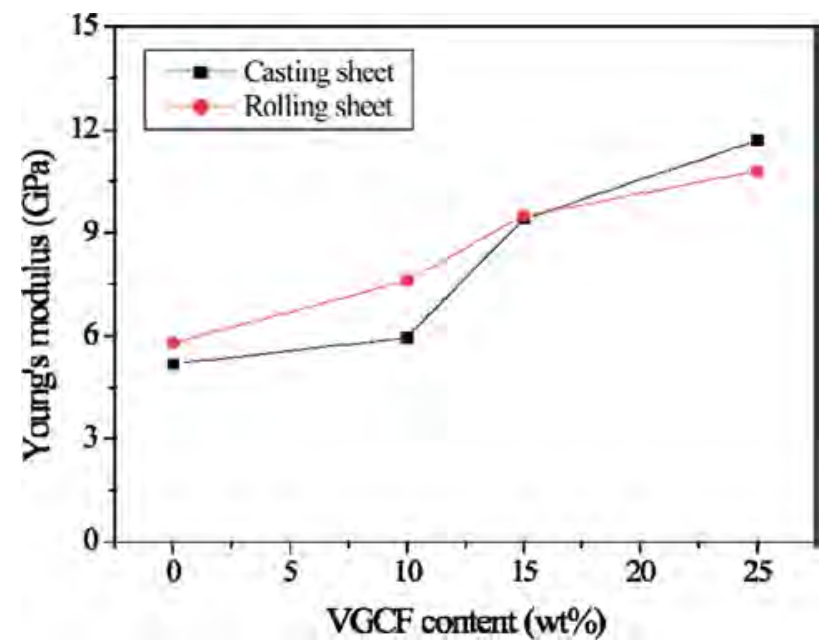

Fig. 24. Young's modulus of polycarbonate/vapor grown carbon fiber (VGCF) cast and rolling composites reinforced with various amount of VGCF [50].

\subsection{Polyetheretherketone resins}

Polyetheretherketone (PEEK) resins are synthesized by stepgrowth polymerization through the dialkylation of bisphenolate salts. Typically, the reaction used is that of 4,4'-difluorobenzophenone combined with the disodium salt of hydroquinone, which is generated in situ by deprotonation by sodium carbonate, as shown in Fig. 25 [51].

PEEK is a semicrystalline thermoplastic with excellent mechanical and chemical resistance properties that are retained even under high temperatures. The Young's modulus is $3.6 \mathrm{GPa}$ and it has a tensile strength of 90 to $100 \mathrm{MPa}$. PEEK has a $\mathrm{T}_{\mathrm{g}}$ occurring at around $143^{\circ} \mathrm{C}$ and melts at roughly $343^{\circ} \mathrm{C}$. PEEK carries a V-0 flammability rating and exhibits very low smoke and toxic gas emission when exposed to flame [52].

PEEK is generally used as an engineering material as it exhibits high strength and low wear, good resistance to corrosion, and the almost unique ability among polymers to operate effectively in an ultra high vacuum environment $[53,54]$.

Gebhard et al. [55] studied the wear of aqueous lubricated SCF reinforced PEEK composites. Fig. 26 shows the fiber corrosion depths of the composites under different experimental and environmental conditions. The fiber corrosion depth of TGC (after a sliding experiment with simultaneous galvanic corrosion) showed the highest value seen in this study. This means that for TGC there is not only an increase in the wear rate due to the occurrence of fiber corrosion, but also a complimentary effect of tribological stress enhanced CF corrosion.

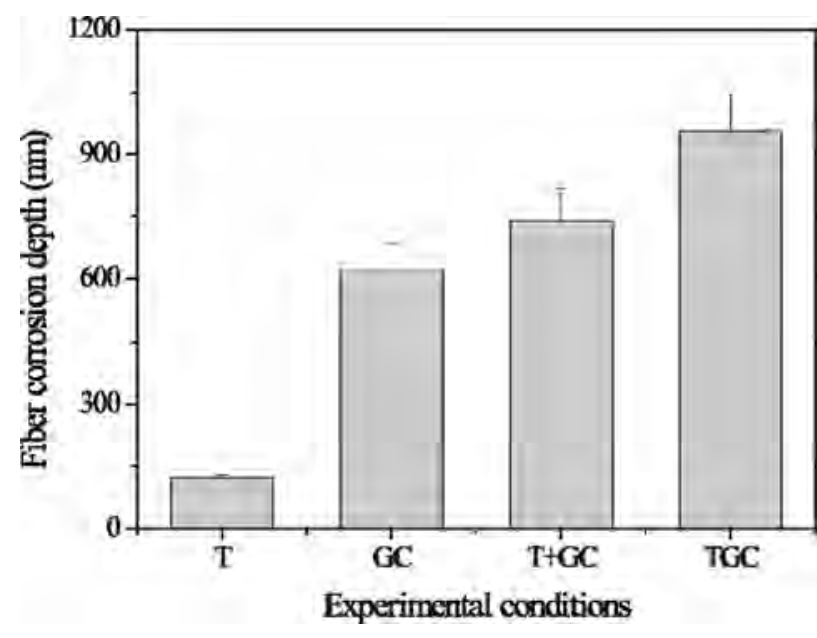

Fig. 26. Fiber corrosion depths of polyetheretherketone vs. stainless steel pairing under different experimental and environmental conditions [55]. T: pure sliding, GC: galvanic corrosion, T+GC: mathematical addition, TGC: sliding experiment with simultaneous galvanic corrosion.<smiles>Cc1cccc(N2C(=O)c3ccc(Oc4ccc(C(C)(C)c5ccc(Oc6ccc7c(c6)C(=O)N(C)C7=O)cc5)cc4)cc3C2=O)c1</smiles>

Fig. 27. Chemical structure of polyetherimide.

\subsection{Polyetherimide resins}

Polyetherimide (PEI) is an amorphous, engineering thermoplastic resin. Fig. 27 shows the chemical structure of PEI. PEI has high heat resistance, excellent electrical properties, high strength and modulus, and excellent processability. The $\mathrm{T}_{\mathrm{g}}$ and amorphous density of PEI at $25^{\circ} \mathrm{C}$ are $216^{\circ} \mathrm{C}$ and $1.27 \mathrm{~g} / \mathrm{cc}$, respectively. Unmodified PEI resin is transparent, and it has inherent flame resistance properties and exhibits low-smoke evolution [56].

PEI can be processed on conventional thermoplastic molding equipment. PEI resin is available for general-purpose injection molding, blow molding, foam molding, and extrusion. PEI is extruded to produce profiles, coated wire, sheet, and film. The addition of glass fiber reinforcement to the PEI provides it with both greater tensile strength and greater rigidity while at the same time improving its dimensional stability [57].

PEI resists a broad range of chemicals under varied conditions of stress and temperatures. PEI is compatible with aliphatic hydrocarbons and alcohols, such as gasoline and gasohol, mineral-salt solutions, dilute bases, and fully halogenated hydrocarbons [58].

Xian and Zhang [59] demonstrated the influence of SCF reinforcement on the sliding wear of PEI composites. Fig. 28 shows the evolution of the specific wear rates with the SCF fraction.<smiles>COc1ccc([N+](=O)[O-])cc1</smiles><smiles>CC(C)(C)Oc1ccc(C(=O)c2ccc(Oc3ccc(C(C)(C)C)cc3)cc2)cc1</smiles>

Fig. 25. Schematic outline for the synthesis of polyetheretherketone. 


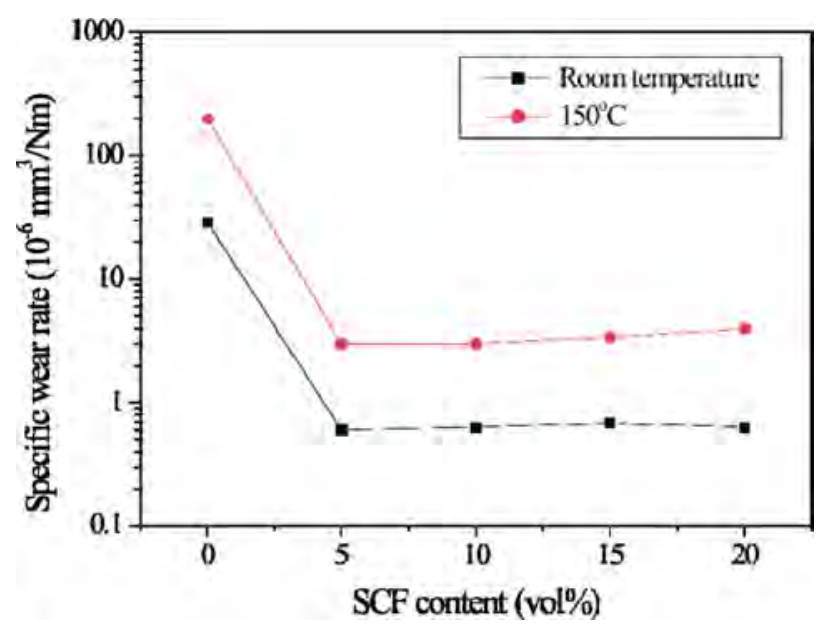

Fig. 28. The specific wear rate of neat polyetherimide and its short carbon fiber (SCF) composites at room temperature and $150^{\circ} \mathrm{C}$, measured with a pin-on-disc testing rig, $1 \mathrm{~m} / \mathrm{s}$, and $2 \mathrm{MPa}$ [59].

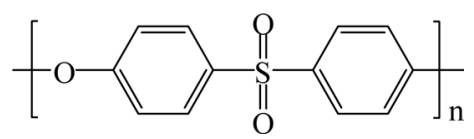

Fig. 29. Chemical structure of polyethersulfone.

They found that the addition of SCF could reduce the specific wear rate of PEI by around 60 times at room temperature and 80 times at $150^{\circ} \mathrm{C}$, which is due to the reinforcing, lubricating, and thermal conducting functions of SCF.

\subsection{Polyethersulfone resins}

Polyethersulfone (PES) is an excellent heat resistant, transparent, non-crystalline engineering plastic containing ether groups and sulfone groups in its backbone chains. Fig. 29 shows the chemical structure of PES.

PES resins have high temperature performance and a high $\mathrm{T}_{\mathrm{g}}$, good dimensional stability, outstanding rigidity even at high temperature, excellent insulation properties, are biocompatible, and are inherently flame retardant [60].

PES can be molded on conventional plastics processing equipment such as injection molding, extrusion, compression molding, solution casting, and sintering. Because of its amorphous nature, PES has excellent dimensional stability and it can be easily processed with highly polar solvents, so it is suitable for applications requiring close tolerances and little dimensional change over a wide temperature range. PES composites offer distinct advantages over thermosets: shorter processing time, better toughness, reduced storage and scrap, and ability to be repaired [56].

$\mathrm{Wu}$ and Schultz [56] studied the processing and properties of solution impregnated CF-reinforced PES composites. The results indicated that a higher molding temperature and longer molding time increased flexural strength from $44 \mathrm{MPa}$ to $71 \mathrm{MPa}$.

\subsection{Polyethylene resins}

Polyethylene (PE) is a thermoplastic polymer consisting of long chains of the monomer ethylene, as shown in Fig. 30. PE is

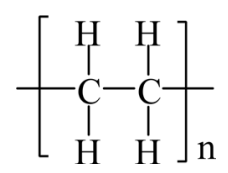

Fig. 30. Chemical structure of polyethylene.

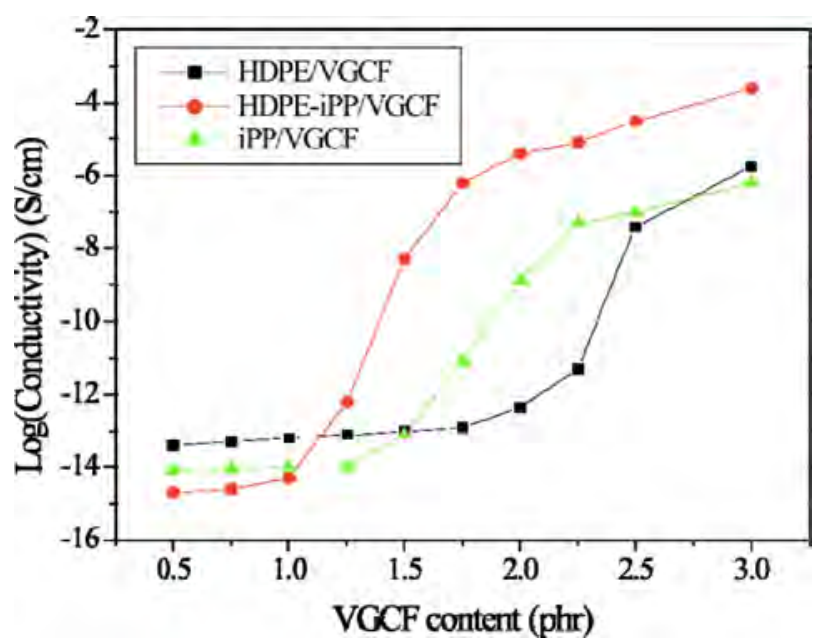

Fig. 31. Dependence of electrical conductivity on vapor grown carbon fiber (VGCF) content for VGCF filled high density polyethylene (HDPE), isotactic polypropylene (iPP), and HDPE/iPP (50/50) blends molded at $190^{\circ} \mathrm{C}$ for $15 \mathrm{~min}$ [64].

a light, versatile synthetic resin made from the polymerization of ethylene. PE can be produced by radical polymerization, anionic addition polymerization, cationic addition polymerization, or ion coordination polymerization. Its simple basic structure can be linear or may be branched to a greater or lesser degree.

$\mathrm{PE}$ is a member of the important family of polyolefin resins. It is the most widely used plastic in the world. It has been made into products ranging from clear food wrap and shopping bags to detergent bottles and automobile fuel tanks. It can also be slit or spun into synthetic fibers or modified to take on the elastic properties of rubber [61].

$\mathrm{PE}$ is available in a range of flexibilities and physical properties depending on the production process. PE can be formed by a wide variety of thermoplastic processing methods and is particularly useful where moisture resistance and low cost are required.

The mechanical properties of PE depend significantly on variables such as the extent and type of branching, the crystal structure, and the molecular weight. PE is classified into low density PE (LDPE), linear low density PE (LLDPE), high density PE (HDPE), etc. LDPE, LLDPE, and HDPE typically have density values ranging from 0.91 to $0.925 \mathrm{~g} / \mathrm{cm}^{3}, 0.918$ to $0.94 \mathrm{~g} / \mathrm{cm}^{3}$, and 0.935 to $0.96 \mathrm{~g} / \mathrm{cm}^{3}$, respectively $[62,63]$.

Zhang et al. [64] demonstrated the selective location and double percolation of CF filled HDPE/isotactic polypropylene (iPP) blends. Fig. 31 shows the dependence of the electrical conductivity on VGCF content for HDPE, iPP, and HDPE/iPP blends. The HDPE samples exhibit a percolation threshold at $2.5 \mathrm{phr}$ (parts per hundred parts resin) VGCF content, whereas for the iPP samples, the percolation threshold is $1.75 \mathrm{phr}$ VGCF content. This is due to the different filler dispersion states of the two polymers. 


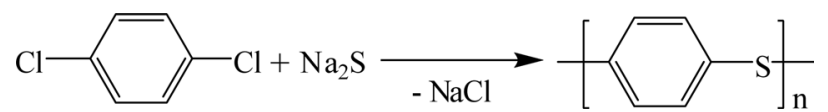

Fig. 32. Schematic outline for the synthesis of polyphenylene sulfide.

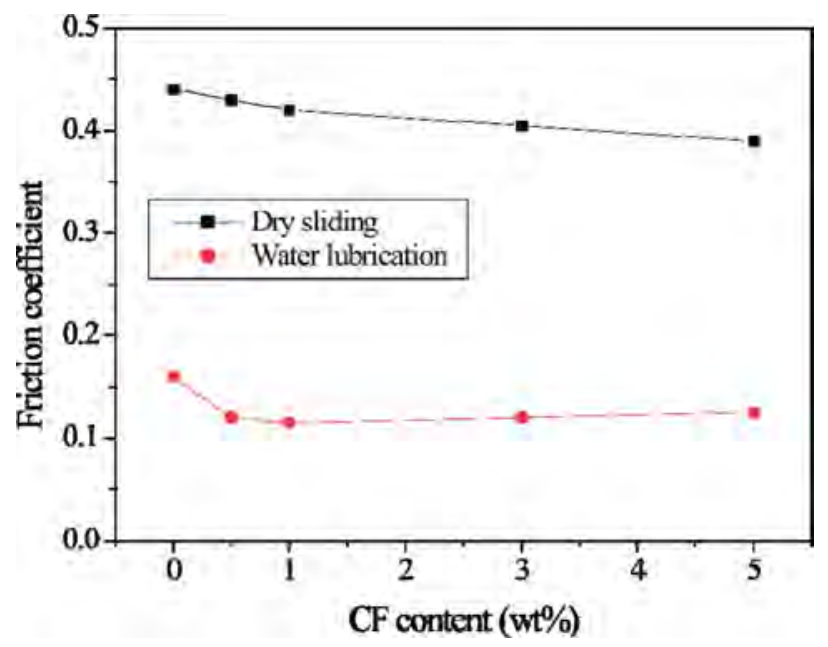

Fig. 33. Variations in friction coefficient of polyphenylene sulfide/carbon fiber (CF) composite coating as a function of CF content [66].

\subsection{Polyphenylene sulfide resins}

Polyphenylene sulfide (PPS) is formed by the reaction of sodium sulfide with p-dichlorobenzene as shown in Fig. 32. PPS is an organic polymer having a symmetrical rigid backbone chain consisting of recurring p-substituted benzene rings and sulfur atoms. PPS is a semicrystalline, high-performance engineering thermoplastic.

PPS exhibits outstanding chemical resistance, thermal stability, dimensional stability, and fire resistance. PPS's extreme inertness toward organic solvents, and inorganic salts and bases accounts for its outstanding performance as a corrosion-resistant coating suitable for contact with foods [65].

PPS can be molded, extruded, or machined to high tolerances. In its pure solid form, it may be opaque white to light tan in color. PPS resins are available as powders for slurry coating and electrostatic spraying. Because of its low viscosity, PPS can be molded with a high loading of fillers and reinforcements. This is needed to compensate for its inherent brittleness.

$\mathrm{Xu}$ et al. [66] studied the tribological behavior of PPS/CF composite coating under dry sliding and water lubrication. Fig. 33 shows the variations in the friction coefficient of the composite coating with the content of $\mathrm{CF}$ at a sliding speed of 0.43 $\mathrm{m} / \mathrm{s}$ under $200 \mathrm{~N}$. It showed that the friction coefficient of the composite coating appeared to decrease slightly with increasing CF content both under dry- and water-lubricated conditions. At the same time, the friction coefficient under the water-lubricated condition was much lower than that under dry sliding.

\subsection{Polypropylene resins}

Polypropylene (PP) is a thermoplastic polymer with a linear structure made from the monomer propylene by Ziegler-Natta

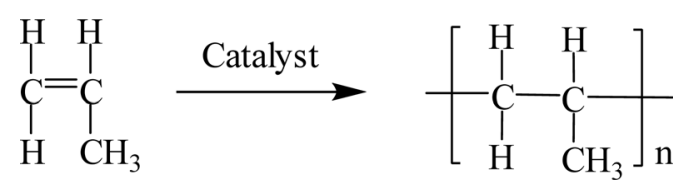

Fig. 34. Schematic outline for the synthesis of polypropylene.

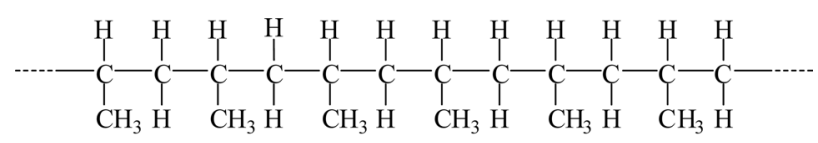

(a) Isotactic PP

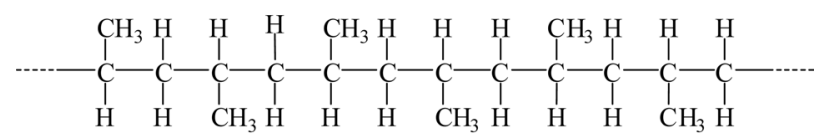

(b) Atactic PP

Fig. 35. Chemical structures of isotactic and atactic polypropylens (PPs).

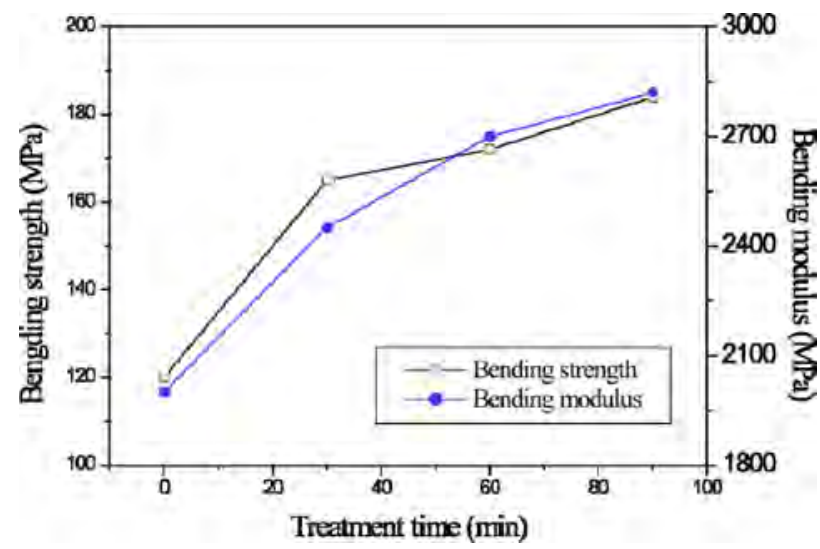

Fig. 36. Bending strength and modulus of polypropylen/carbon fiber composites [73].

polymerization and by metallocene catalysis polymerization as shown in Fig. 34.

Short segments of PP show examples of isotactic and syndiotactic tacticity as shown in Fig. 35.

PP resins are cheap and have low densities $\left(0.90-0.92 \mathrm{~g} / \mathrm{cm}^{3}\right)$ and high tensile and compressive strength. They have a melting point of $160^{\circ} \mathrm{C}$, excellent dielectric properties, and are nontoxic. They are used in a wide variety of applications including packaging and labeling, textiles, stationery, plastic parts and reusable containers of various types, laboratory equipment, loudspeakers, automotive components, and polymer banknotes. In addition, these polymers made from the monomer propylene are unusually resistant to many chemical solvents, bases, and acids [67-69].

In general, homopolymers can be used for housing, housewares, packaging, cassette holders and fibers, monofilaments, and film tapes; copolymers are preferred for all applications exposed to cold. Copolymers are widely used for pipes, containers, boat hulls, seat shells, and automotive parts.

In order to improve some of the physical properties of PP, 
PP formulas may include additives, such as pigments, carbon black, rubbers, antioxidants, and UV stabilizers. PP is available as molding powder, extruded sheet, cast film, textile staple, and continuous filament yarn [70-72].

Li [73] demonstrated the interfacial compatibility of PP composites filled with surface treated CF. Fig. 36 shows the threepoint bending value of $\mathrm{PP} / \mathrm{CF}$ composites as a function of treatment time. The bending strength and modulus increase with an increasing treatment time, which indicates that the interfacial adhesion between the CF and the PP matrix increases with treatment time.

\section{Conclusions}

In this paper, we reviewed the synthesis and properties of thermosetting and thermoplastic resins. The role of the polymer matrix in CF-reinforced composites is to provide bulk to the composite laminate and transfer load between fibers. Selection of a suitable polymer matrix plays an important role in the specific applications of the composites. CF-reinforced polymer composites are of great interest as multifunctional high-performance materials for use in structural and thermal protection applications.

\section{Acknowledgements}

This work was supported by the Small and Medium Business Administration and published as a chapter of the book 'Carbon fibers.'

\section{References}

[1] Barton JM, Hamerton I, Jones JR, Stedman JC. Mechanical properties of tough, high temperature carbon fibre composites from novel functionalized aryl cyanate ester polymers. Polymer, 37, 4519 (1996). http://dx.doi.org/10.1016/0032-3861(96)00053-5.

[2] Marieta C, Schulz E, Mondragon I. Characterization of interfacial behaviour in carbon-fibre/cyanate composites.Compos Sci Technol, 62, 299 (2002). http://dx.doi.org/10.1016/S02663538(01)00215-9.

[3] Ren P, Liang G, Zhang Z. Influence of epoxy sizing of carbon-fiber on the properties of carbon fiber/cyanate ester composites.Polym Compos, 27, 591 (2006). http://dx.doi.org/10.1002/pc.20230.

[4] Chung K, Seferis JC. Evaluation of thermal degradation on carbon fiber/cyanate ester composites. Polym Degrad Stab, 71, 425 (2001). http://dx.doi.org/10.1016/S0141-3910(00)00194-4.

[5] Thunga M, Lio WY, Akinc M, Kessler R. Adhesive repair of bismaleimide/carbon fiber composites with bisphenol $\mathrm{E}$ cyanate ester. Compos Sci Technol, 71, 239 (2011). http://dx.doi.org/10.1016/j. compscitech.2010.11.021.

[6] Jin FL, Ma CJ, Park SJ. Thermal and mechanical interfacial properties of epoxy composites based on functionalized carbon nanotubes. Mater Sci Eng A, 528, 8517 (2011). http://dx.doi. org/10.1016/j.msea.2011.08.054.

[7] Zhu L, Jin FL, Park SJ. Thermal stability and fracture toughness of epoxy resins modified with epoxidized castor oil and $\mathrm{Al}_{2} \mathrm{O}_{3}$ nanoparticles. Bull Korean Chem Soc, 33, 2513 (2012). http:// dx.doi.org/10.5012/bkcs.2012.33.8.2513.

[8] Park SJ, Kim MH, Lee JR, Choi S. Effect of fiber-polymer interactions on fracture toughness behavior of carbon fiber-reinforced epoxy matrix composites. J Colloid Interf Sci, 228, 287 (2000). http://dx.doi.org/10.1006/jcis.2000.6953.

[9] Yoo MJ, Kim SH, Park SD, Lee WS, Sun JW, Choi JH, Nahm S. Investigation of curing kinetics of various cycloaliphatic epoxy resins using dynamic thermal analysis. Eur Polym J, 46, 1158 (2010). http://dx.doi.org/10.1016/j.eurpolymj.2010.02.001.

[10] Park SJ, Kim TJ, Lee JR. Cure behavior of diglycidylether of bisphenol A/trimethylolpropane triglycidylether epoxy blends initiated by thermal latent catalyst. J Polym Sci B, 38, 2114 (2000). http:// dx.doi.org/10.1002/1099-0488(20000815)38:16<2114::AIDPOLB50>3.0.CO;2-8.

[11] Kwak GH, Park SJ, Lee JR. Thermal stability and mechanical behavior of cycloaliphatic-DGEBA epoxy blend system initiated by cationic latent catalyst. J Appl Polym Sci, 78, 290 (2000). http://dx.doi.org/10.1002/1097-4628(20001010)78:2<290::AIDAPP80>3.0.CO;2-9.

[12] Park SJ, Jin FL, Lee JR. Thermal and mechanical properties of tetrafunctional epoxy resin toughened with epoxidized soybean oil. Mater Sci Eng A, 374, 109 (2004). http://dx.doi.org/10.1016/j. msea.2004.01.002

[13] Lee MC, Ho TH, Wang CS. Synthesis of tetrafunctional epoxy resins and their modification with polydimethylsiloxane for electronic application. J Appl Polym Sci, 62, 217 (1996). http:// dx.doi.org/10.1002/(SICI)1097-4628(19961003)62:1<217::AIDAPP25>3.0.CO;2-0.

[14] Chen W, Yu Y, Li P, Wang C, Zhou T, Yang X. Effect of new epoxy matrix for T800 carbon fiber/epoxy filament wound composites Compos Sci Technol, 67, 2261 (2007). http://dx.doi.org/10.1016/j. compscitech.2007.01.026.

[15] Miloshev S, Novakov P, Dimitrov V, Gitsov I. Synthesis of novolac resins: 2. Influence of the reaction medium on the properties of the novolac oligomers. Polymer, 32, 3067 (1991). http://dx.doi org/10.1016/0032-3861(91)90211-Z.

[16] Park SJ, Seo MK, Lee JR. Isothermal cure kinetics of epoxy/ phenol-novolac resin blend system initiated by cationic latent thermal catalyst. J Polym Sci A, 38, 2945 (2000). http:// dx.doi.org/10.1002/1099-0518(20000815)38:16<2945::AIDPOLA120>3.0.CO;2-6.

[17] Guo B, Jia D, Fu W, Qiu Q. Hygrothermal stability of dicyanatenovolac epoxy resin blends. Polym Degrad Stab, 79, 521 (2003). http://dx.doi.org/10.1016/S0141-3910(02)00368-3.

[18] Xu HJ, Jin FL, Park SJ. Synthesis of a novel phosphorus-containing flame retardant for epoxy resins. Bull Korean Chem Soc, 30, 2643 (2009). http://dx.doi.org/10.5012/bkcs.2009.30.11.2643.

[19] Park SJ, Jin FL. Thermal stabilities and dynamic mechanical properties of sulfone-containing epoxy resin cured with anhydride Polym Degrad Stab, 86, 515 (2004). http://dx.doi.org/10.1016/j. polymdegradstab.2004.06.003

[20] Park SJ, Jin FL, Lee JR. Synthesis and thermal properties of epoxidized vegetable oil. Macromol Rapid Commun, 25, 724 (2004) http://dx.doi.org/10.1002/marc.200300191.

[21] Park SJ, Jin FL, Lee JR, Shin JS. Cationic polymerization and physicochemical properties of a biobased epoxy resin initiated by thermally latent catalysts. Eur Polym J, 41, 231 (2005). http:// dx.doi.org/10.1016/j.eurpolymj.2004.09.011. 
[22] Park SJ, Jin FL, Shin JS. Physicochemical and mechanical interfacial properties of trifluorometryl groups containing epoxy resin cured with amine. Mater Sci Eng A, 390, 240 (2005). http://dx.doi. org/10.1016/j.msea.2004.08.022

[23] Park SJ, Jin FL. Synthesis and characterization of UV-curable acrylic resins containing fluorine groups. Polym Int, 54, 705 (2005). http://dx.doi.org/10.1002/pi.1755.

[24] Park SJ, Jin FL, Nicolais L. Epoxy resins: fluorine systems. In: Nicolais L, Borzacchiello A, eds. Wiley encyclopedia of composites, John Wiley \& Sons (2011). http://dx.doi.org/10.1002/ 9781118097298.weoc076.

[25] Choi MH, Jeon BH, Chung IJ. The effect of coupling agent on electrical and mechanical properties of carbon fiber/phenolic resin composites. Polymer, 41, 3243 (2000). http://dx.doi.org/10.1016/ S0032-3861(99)00532-7.

[26] Park SJ, Jang YS. Interfacial characteristics and fracture toughness of electrolytically Ni-plated carbon fiber-reinforced phenolic resin matrix composites. J Colloid Interf Sci, 237, 91 (2001). http:// dx.doi.org/10.1006/jcis.2001.7441.

[27] An H, Feng B, Su S. $\mathrm{CO}_{2}$ capture capacities of activated carbon fibre-phenolic resin composites. Carbon, 47, 2396 (2009). http:// dx.doi.org/10.1016/j.carbon.2009.04.029.

[28] Fei J, Li HJ, Fu YW, Qi LH, Zhang YL. Effect of phenolic resin content on performance of carbon fiber reinforced paper-based friction material. Wear, 269, 534 (2010). http://dx.doi.org/10.1016/j. wear.2010.05.008.

[29] Hsiao KT, Gangireddy S. Investigation on the spring-in phenomenon of carbon nanofiber-glass fiber/polyester composites manufactured with vacuum assisted resin transfer molding. Composites A, 39, 834 (2008). http://dx.doi.org/10.1016/j.compositesa.2008.01.015

[30] Cecen V, Sarikanat M, Seki Y, Govsa T, Yildiz H, Tavman IH. Polyester composites reinforced with noncrimp stitched carbon fabrics: Mechanical characterization of composites and investigation on the interaction between polyester and carbon fiber. J Appl Polym Sci, 102, 4554 (2006). http://dx.doi.org/10.1002/app.24983.

[31] Monti M, Natali M, Petrucci R, Kenny JM, Torre L. Carbon nanofibers for strain and impact damage sensing in glass fiber reinforced composites based on an unsaturated polyester resin. Polym Compos, 32, 766 (2011). http://dx.doi.org/10.1002/pc.21098

[32] Vilcakova J, Saha P, Quadrat O. Electrical conductivity of carbon fibres/polyester resin composites in the percolation threshold region. Eur Polym J, 38, 2343 (2002). http://dx.doi.org/10.1016/ S0014-3057(02)00145-3.

[33] Zhang XR, Pei XQ, Wang QH. Friction and wear studies of polyimide composites filled with short carbon fibers and graphite and micro $\mathrm{SiO}_{2}$. Mater Design, 30, 4414 (2009). http://dx.doi. org/10.1016/j.matdes.2009.04.002.

[34] Samyn P, Schoukens G. Thermochemical sliding interactions of short carbon fiber polyimide composites at high pv-conditions Mater Chem Phys, 115, 185 (2009). http://dx.doi.org/10.1016/j. matchemphys.2008.11.029.

[35] Mascia L, Zhang Z, Shaw SJ. Carbon fibre composites based on polyimide/silica ceramers: aspects of structure-properties relationship. Composites A, 27, 1211 (1996). http://dx.doi.org/10.1016/ 1359-835X(96)00082-6.

[36] Li J, Cheng XH. Friction and wear properties of surface-treated carbon fiber-reinforced thermoplastic polyimide composites under oil-lubricated condition. Mater Chem Phys, 108, 67 (2008). http:// dx.doi.org/10.1016/j.matchemphys.2007.09.003.

[37] Broyles NS, Verghese KNE, Davis SV, Li H, Davis RM, Lesko JJ, Riffle JS. Fatigue performance of carbon fibre/vinyl ester composites: the effect of two dissimilar polymeric sizing agents. Polymer 39, 3417 (1998). http://dx.doi.org/10.1016/S0032-3861(97)10078-

[38] Vautard F, Ozcan S, Meyer H. Properties of thermo-chemically surface treated carbon fibers and of their epoxy and vinyl ester composites. Composites A, 43, 1120 (2012). http://dx.doi. org/10.1016/j.compositesa.2012.02.018.

[39] Jin FL, Rhee KY, Park SJ. Surface treatment of montmorillonite on the thermal stabilities of bisphenol-A diglycidyl dimethacrylate nanocomposites. Mater Sci Eng A, 435-436, 429 (2006). http:/ dx.doi.org/10.1016/j.msea.2006.07.071.

[40] Yamada K, Yamane H, Kumada K, Tanabe S, Kajiyama T. Plasmagraft polymerization of a monomer with double bonds onto the surface of carbon fiber and its adhesion to a vinyl ester resin. J Appl Polym Sci, 90, 2415 (2003). http://dx.doi.org/10.1002/app.12897.

[41] Huang CY, Wu CC. The EMI shielding effectiveness of PC/ABS/ nickel-coated-carbon-fibre composites. Eur Polym J, 36, 2729 (2000). http://dx.doi.org/10.1016/S0014-3057(00)00039-2.

[42] Li J, Cai CL. The carbon fiber surface treatment and addition of PA6 on tensile properties of ABS composites. Curr Appl Phys, 11, 50 (2011). http://dx.doi.org/10.1016/j.cap.2010.06.017.

[43] Wu SH, Wang FY, Ma CCM, Chang WC, Kuo CT, Kuan HC, Chen WJ. Mechanical, thermal and morphological properties of glass fiber and carbon fiber reinforced polyamide- 6 and polyamide- 6 / clay nanocomposites. Mater Lett, 49, 327 (2001). http://dx.doi. org/10.1016/S0167-577X(00)00394-3.

[44] Botelho EC, Figiel L, Rezende MC, Lauke B. Mechanical behavior of carbon fiber reinforced polyamide composites. Compos Sci Technol, 63, 1843 (2003). http://dx.doi.org/10.1016/S02663538(03)00119-2

[45] Feldman AY, Gonzalez MF, Wachtel E, Moret MP, Marom G. Transcrystallinity in aramid and carbon fiber reinforced nylon 66: determining the lamellar orientation by synchrotron X-ray micro diffraction. Polymer, 45, 7239 (2004). http://dx.doi.org/10.1016/j. polymer.2004.08.027.

[46] Senthilvelan S, Gnanamoorthy R. Damping characteristics of unreinforced, glass and carbon fiber reinforced nylon 6/6 spur gears Polym Test, 25, 56 (2006). http://dx.doi.org/10.1016/j.polymertesting.2005.09.005.

[47] Montes-Moran MA, Martinez-Alonso A, Tascon JMD, Paiva MC, Bernardo CA. Effects of plasma oxidation on the surface and interfacial properties of carbon fibres/polycarbonate composites. Carbon, 39, 1057 (2001). http://dx.doi.org/10.1016/S00086223(00)00220-7.

[48] Carneiro OS, Covas JA, Bernardo CA, Caldeira G, Hattum FWJV Ting JM, Alig RL, Lake ML. Production and assessment of polycarbonate composites reinforced with vapour-grown carbon fibres. Compos Sci Technol, 58, 401 (1998). http://dx.doi.org/10.1016/ S0266-3538(97)00138-3.

[49] Park JM. Interfacial properties of two-carbon fiber reinforced polycarbonate composites using two-synthesized graft copolymers as coupling agents. J Colloid Interf Sci, 225, 384 (2000). http:// dx.doi.org/10.1006/jcis.2000.6733.

[50] Choi YK, Sugimoto K, Song SM, Endo M. Production and characterization of polycarbonate composite sheets reinforced with vapor grown carbon fiber. Composites A, 37, 1944 (2006). http://dx.doi. 
org/10.1016/j.compositesa.2005.12.026.

[51] Kurtz SM. Chapter 2-Synthesis and processing of PEEK for surgical implants. In: Kurtz SM, ed. PEEK Biomaterials Handbook, William Andrew Publishing, Oxford, 9 (2012). http://dx.doi. org/10.1016/B978-1-4377-4463-7.10002-8

[52] Ma CCM, Tai NH, Wu SH, Lin SH, Wu JF, Lin JM. Creep behavior of carbon-fiber-reinforced polyetheretherketone (PEEK) $[ \pm 45]_{4}$ laminated composites (I). Composites B, 28, 407 (1997). http:// dx.doi.org/10.1016/S1359-8368(96)00059-5.

[53] Xie GY, Sui GX, Yang R. Effects of potassium titanate whiskers and carbon fibers on the wear behavior of polyetheretherketone composite under water lubricated condition. Compos Sci Technol, 71, 828 (2011). http://dx.doi.org/10.1016/j.compscitech.2011.01.019.

[54] Gebhard A, Bayerl T, Schlarb AK, Friedrich K. Galvanic corrosion of polyacrylnitrile (PAN) and pitch based short carbon fibres in polyetheretherketone (PEEK) composites. Corros Sci, 51, 2524 (2009). http://dx.doi.org/10.1016/j.corsci.2009.05.051.

[55] Gebhard A, Bayerl T, Schlarb AK, Friedrich K. Increased wear of aqueous lubricated short carbon fiber reinforced polyetheretherketone (PEEK/SCF) composites due to galvanic fiber corrosion. Wear, 268, 871 (2010). http://dx.doi.org/10.1016/j.wear.2009.11.018.

[56] Wu GM, Schultz JM. Processing and properties of solution impregnated carbon fiber reinforced polyethersulfone composites. Polym Compos, 21, 223 (2000). http://dx.doi.org/10.1002/pc.10179.

[57] Hou M, Ye L, Lee HJ, Mai YW. Manufacture of a carbon-fabricreinforced polyetherimide (CF/PEI) composite material. Compos Sci Technol, 58, 181 (1998). http://dx.doi.org/10.1016/S02663538(97)00117-6.

[58] Kim KY, Ye L. Interlaminar fracture toughness of CF/PEI composites at elevated temperatures: roles of matrix toughness and fibre/matrix adhesion. Composites A, 35, 477 (2004). http://dx.doi. org/10.1016/j.compositesa.2003.10.005.

[59] Xian G, Zhang Z. Sliding wear of polyetherimide matrix composites: I. Influence of short carbon fibre reinforcement. Wear, 258, 776 (2005). http://dx.doi.org/10.1016/j.wear.2004.09.054.

[60] Fernandez B, Arbelaiz A, Diaz E, Mondragon I. Influence of polyethersulfone modification of a tetrafunctional epoxy matrix on the fracture behavior of composite laminates based on woven carbon fibers. Polym Compos, 25, 480 (2004). http://dx.doi.org/10.1002/ pc.20041.

[61] Peijs AAJM. de Kok JMM. Hybrid composites based on polyethylene and carbon fibers. Part 6: Tensile and fatigue behavior. Composites, 24, 19 (1993). http://dx.doi.org/10.1016/0010-4361(93)90260-F.

[62] Hertel D, Valette R, Munstedt H. Three-dimensional entrance flow of a low-density polyethylene (LDPE) and a linear low-density polyethylene (LLDPE) into a slit die. J Non-Newton Fluid Mech,
153, 82 (2008). http://dx.doi.org/10.1016/j.jnnfm.2007.11.010.

[63] Spencer MW, Cui L, Yoo Y, Paul DR. Morphology and properties of nanocomposites based on HDPE/HDPE-g-MA blends. Polymer, 51, 1056 (2010). http://dx.doi.org/10.1016/j.polymer.2009.12.047.

[64] Zhang C, Yi XS, Yui H, Asai S, Sumita M. Selective location and double percolation of short carbon fiber filled polymer blends: high-density polyethylene/isotactic polypropylene. Mater Lett, 36, 186 (1998). http://dx.doi.org/10.1016/S0167-577X(98)00023-8.

[65] Jiang Z, Gyurova LA, Schlarb AK, Friedrich K, Zhang Z. Study on friction and wear behavior of polyphenylene sulfide composites reinforced by short carbon fibers and sub-micro $\mathrm{TiO}_{2}$ particles. Compos Sci Technol, 68, 734 (2008). http://dx.doi.org/10.1016/j. compscitech.2007.09.022.

[66] Xu H, Feng Z, Chen J, Zhou H. Tribological behavior of the carbon fiber reinforced polyphenylene sulfide (PPS) composite coating under dry sliding and water lubrication. Mater Sci Eng A, 416, 66 (2006). http://dx.doi.org/10.1016/j.msea.2005.09.094.

[67] Karsli NG, Aytac A, Akbulut M, Deniz V, Guven O. Effects of irradiated polypropylene compatibilizer on the properties of short carbon fiber reinforced polypropylene composites. Radiat Phys Chem, 84, 74 (2013). http://dx.doi.org/10.1016/j.radphyschem.2012.06.041.

[68] Dutra RCL, Soares BG, Campos EA, Silva JLG. Hybrid composites based on polypropylene and carbon fiber and epoxy matrix. Polymer, 41, 3841 (2000). http://dx.doi.org/10.1016/S00323861(99)00552-2.

[69] Karsli NG, Aytac A. Effects of maleated polypropylene on the morphology, thermal and mechanical properties of short carbon fiber reinforced polypropylene composites. Mater Design, 32, 4069 (2011). http://dx.doi.org/10.1016/j.matdes.2011.03.021.

[70] Taketa I, Ustarroz J, Gorbatikh L, Lomov SV, Verpoest I. Interply hybrid composites with carbon fiber reinforced polypropylene and self-reinforced polypropylene. Composites A, 41, 927 (2010). http://dx.doi.org/10.1016/j.compositesa.2010.02.003.

[71] Rezaei F, Yunus R, Ibrahim NA. Effect of fiber length on thermomechanical properties of short carbon fiber reinforced polypropylene composites. Mater Design, 30, 260 (2009). http://dx.doi. org/10.1016/j.matdes.2008.05.005.

[72] Fu SY, Lauke B, Mader E, Hu X, Yue CY. Fracture resistance of short-glass-fiber-reinforced and short-carbon-fiber-reinforced polypropylene under Charpy impact load and its dependence on processing. J Mater Process Technol, 89-90, 501 (1999). http:// dx.doi.org/10.1016/S0924-0136(99)00065-5.

[73] Li J. The research on the interfacial compatibility of polypropylene composite filled with surface treated carbon fiber. Appl Surf Sci, 255, 8682 (2009). http://dx.doi.org/10.1016/j.apsusc.2009.06.053. 